\title{
Design of the Integrated Talent Training Mode of Bachelor-Master-Doctor on Labor Economics
}

\author{
Wei Wang, Yonghui Deng, Ping Li, Yingzhe Wang \\ School of Finance and Public Administration \\ Harbin University of Commerce \\ Harbin, China \\ 63993022@qq.com
}

\begin{abstract}
The impact of technological change on economy and society has forced higher education institutions to give urgently respond. Currently, knowledge structure and ability level has great differences among Bachelor--Master-Doctor(BMD).This paper aims to design cross-level, cross-group, and cross-task connotation talent training mode. And it has applied qualitative analysis methods to design the integrated talent training mode of BMD, based on basic principles, and the composition of elements. Through analysis, we have reached a conclusion that integrated talent training model of BMD helps universities to provide comprehensive talents for society.
\end{abstract}

Keywords-Bachelor-Master-Doctor; integration; talent training mode

\section{INTRODUCTION}

Education reform and development has entered a new era in China. It is urgent to improve the institutional mechanisms for promoting the connotation of higher education. Different types of colleges and universities should provide innovative, compound, and applied talents for the need of society, with innovation and entrepreneurship throughout the entire process of personnel training. To the rapidly changing world, whether it is the scholars or the higher institutions, realized that the mode of unilaterally imparted, flattened, and broadcast-liked talent training in higher education institutions is fail to stimulating the undergraduates' motivation for learning under the popularization of higher education, which also fail to meet the needs society for innovative, compound, and applied talents.

From the history of creation and evolution, the world's higher education has experienced continuous changing from system identity, function expansion, to connotation development ${ }^{[1]}$. The connotative development of higher education in China is a historical and periodical concept, which can be mainly divided into two stages with 2002 as the boundary. The first stage can be conclude to quantity scale theory $^{[2][3]}$, from the college entrance examination system was reinstated in 1977, to popularization of higher education in 2002, the second stage is after 2002, mainly means to quality benefit theory ${ }^{[4][5]}$, which through structural adjustment, optimizing resource allocation, and improving the overall quality of teachers and students. And quality-centered comprehensive results theory ${ }^{[6]}$, which means high-quality

Supported by the Foundation of The 13th Five-Year Plan for Educational Science in Heilongjiang Province (GBB1317046);

Higher Education Teaching Reform in Heilongjiang Province

(SJGY20170050); Teaching Reform and Research Project of Harbin

University of Commerce (HSDJY2017010) talents, high-level scientific research, high efficiency of social services, and high efficiency in cultural heritage and innovation, to some extent, that are relative development theory ${ }^{[1]}$, rather than scale development, homogeneous development, and imitative development.

The training model for colleges and universities is a combination of talent training objectives, training methods, and evaluation models and patterns ${ }^{[7][8]}$. In the study of the talent training models, it is necessary to change inheritance type, submissive type, conforming shape, and requirements, that from the requirements of standardization and scale-up of education during the industrial economic period, to complex, application, and innovative talent ${ }^{[9][10]}$, in terms of cultivating goals. The focuses of undergraduate education reform rely on talent training mode. Colleges and universities should increase the proportion of general education and interdisciplinary education, so that the tamed sheep and the exquisite egoists could accept full person education, and became full-fledged ones who learns to study, learns to live, learns to do things, and learns to survive. ${ }^{[11]}$

For training modes, learning is the process of knowledge construction and meaning formulation rather than acceptance and absorption. For more than half a century, the value of higher education has been characterized by scientism and pragmatism in China. The traditional talent training mode is indoctrination style, the transmitting to accepting mode leads short of subjectivity and initiative. However, innovation is a positive thinking activity, a strong lack of subjectivity and initiative lead to passive innovation of undergraduate students ${ }^{[12][13]}$. It is necessary to cultivate innovative talents who focus on the real world, can actively participate in exploration, and have critical thinking ability through question-centered research-based teaching ${ }^{[14]}$. In order to transform extended development to connotative development of talent training, higher education should strengthen collaborative innovation in the same research field and interdisciplinary field, and combine the single training subject of the universities, industries, and research institutes ${ }^{[15]}$.

\section{PANORAMIC DESign OF INTEGRATED TALENT TRAINING MODE OF B-M-D}

Economic management majors including labor economics, which are highly emphasis on application, the goals and specifications of talent training mode, quality requirements and 
social tasks are different for B-M-D. However, the common quality requirements for professional talents are similar, who has cooperation capabilities, exploration capabilities that senior talents always be need. Overall, through a union team could expand knowledge and accumulate social experience, develop social and expressive capabilities. These general skills will enable students to understand the world better, enhance the confidence to cope with complex life and achieve self-worth value. Finally, give students a lasting inner driving force for growth. Furthermore inspire subjectivity and initiative of B-M$\mathrm{D}$ on different levels, which through the inspiring and support within the same groups and between the different groups, that make talent training mode low cost and high efficiency, from internal, and external synergistic education such as project and practice research.

The integrated talent training mode of B-M-D, which based on the basic rules of the development, dialectics, and unity, considered the needs of society and educated. The behavioral subjects that composed of bachelor, master, and doctor, who working in a specific environment, with a specific ideology and supported by boosters, realize the improvement of the core competencies of the three groups, through specific project implementation, practical investigations, academic exchanges, etc.. Finally, the core competencies and feedback elements are constructed and run to be corrected or tested. Such a cycle continues to improve the talent training mode. (See in Fig.1.).

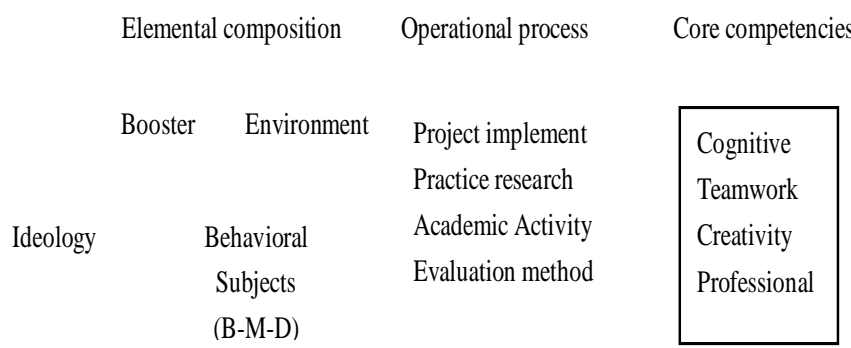

Fig.1. Simplified Model of Integrated Talent Training Mode of "B-M-D"

\section{A. Principles of Integrated Talent Training Mode of B-M-D}

\section{1) Principle of Voluntary and Freedom}

In order to improve the learning ability, scientific research ability, innovation ability, and cooperation ability of different level of students, which contains undergraduates, postgraduates, and doctoral students of labor economics, under the guidance of the college and the discipline, members from the three group, have set up research and practice teams that could name B-M$\mathrm{D}$ union team, follow the principle of voluntary and freedom.

\section{2) Principle of Inspiring and Support}

From the internal of the B-M-D union team of labor economics, the whole process contains teaching, scientific research, academic activities and social practices. With the individual advantage of team members, and subject consciousness and initiative through the inspiring and support within the same groups and between the different groups, we could achieve low cost and high efficiency.
3) Principle of Integrating Knowledge, Ability and Quality

Talent training is the primary function of higher education. The integrated talent training mode of B-M-D is a second classroom model through team building and scientific research. It adhering to the concept of learning in practice and growing in practice, that based on the constructive learning theory, under the coordination of students-students, teacher-student, and within-outside schools, when faced specific issues of the labor economy. And form the ability to build knowledge, participate in practice, we should make rapid respond against changes. Finally, the mode will integrate knowledge, ability and quality training, promote learning through research and application.

\section{4) Principle of Win-Win Cooperation}

From the aspect of three different groups in university, the undergraduates focus on common sense knowledge, the doctors emphasize innovation, and the graduate students are in the middle. These three groups above can complement each other and form a unified community, which have common academic community scope, discipline paradigm, and similar thinking methods. On one hand students in different level could improve knowledge, enhance abilities, and improve personality in solving specific problems, On the other hand, they could achieve integration and do their best in the specific operating practice. Ultimately, we get win-win cooperation and achieve progress together.

\section{B. Elements on Integrated Talent Training Mode of B-M-D}

\section{1) Behavioral Subject}

According to the principle of free combination and organization, B-M-D union team is consist of persons who are highly appreciative in labor economic major. Based on the original theory of classroom learning, under the leadership and organization of the subject group matching in colleges and universities, established an integrated team of scientific research, practical research, academic exchanges, and practical applications with the teachers of this subject group. Doctors are the leaders who puts forward the research direction, and masters are the key figures responsible for design, and with the support of undergraduates do specific implementation, the union team works well. Through project research, social research, doctoral salons, and other specific forms of participatory learning and research-based learning, we enhance students' ability to support lifelong development and meet the requirements of the times. The active participation from B-M$\mathrm{D}$ union team is to ensure the quality of talent training through team building. Through the project research of teachers, practical cases and social experiences of the part-time teachers, the methods of creating and resolving problems are utilized to enable the members of the B-M-D union team to acquire learning ability, scientific research ability, innovation ability, and cooperation ability.

\section{2) Tutor Groups as Boosters}

Tutor groups composed of doctoral tutors, master tutors, and experts from both internal and external academic disciplines. First of all, a systematic theoretical training for the members of the B-M-D union team in preparation for research, scientific research filing, academic exchange, etc. Then, they regularly receive reports from all associations to diagnose and 
analyze emerging and possible problems, help the associations to find problems and define problems, guide them to analyze problems in reflection, and repeatedly precipitate in the next theoretical research and practical investigation. To improve students' ability to reflect on knowledge and practice, to achieve the natural blending of theoretical knowledge and research practice based on true problems, and to obtain action wisdom for solving real problems of the project. Therefore, the tutor group is the role orientation of consultants, mentors, and supervisors in the B-M-D integrated talent training model. It is a booster for the B-M-D union team's self-growth and benign operation.

The composition of the tutor group requires researchoriented teachers who master the laws of education and understand the development of disciplines. They serve as role models for student-based learning, and lead the B-M-D union team to engage with the real process of knowledge. At the same time, they also need to have governments. Dual-qualified talents, such as experts and CEOs of listed companies, combine the entrepreneurial feelings of the entrepreneurs with the needs of the school's teachers, and improve the accuracy of the B-M$\mathrm{D}$ union team of labor economics to the needs of society. And improve the teaching practice. The students' sense of self-worth and mission lays a foundation for students' attention to society and service to the society, and lays a foundation for their ideas, vision and capabilities.

\section{3) The Guaranteed System}

The system is the norm for regulating the relevant people and things in the training of the B-M-D integrated talents, which lays a good foundation for the fair evaluation of each participant and work, provides a basis for performance evaluation, and gradually realizes the scientific and systematic management work. Normalization and standardization provide reliable guarantees. In the stage where the development of higher education has been popularized, the second classroom is opened up through the integration of the B-M-D union team, and the external mechanism of co-producing talents from production, education, and research is used to learn from inside the colleges and universities through team building and scientific research. Optimizing the resource allocation for talent training is an exploration of talent cultivation with low internal training costs, high efficiency, and obvious improvement effect.

The B-M-D union team expands the scope and allocation efficiency of educational resources. It is a mutually-reliant and mutually-reliable behavior in which student groups rely on each other and to achieve a sense of belonging among participating students. However, it is necessary to use incentive mechanisms at the institutional level to solve the utilitarianism of the subject. Sexual needs, more pragmatic results, and a sense of accomplishment for the students will be beneficial to the continued development of the Commonwealth.

Firstly, for undergraduates, they have the right to choose whether to participate in the association, participate in and complete the survey data and generalize credits for elective courses. At the same time; social surveys, academic discussions, and scientific research experience will benefit graduates of undergraduates and masters. The writing of the paper is conducive to the successful graduation of the two.
Secondly, for undergraduates and postgraduates, when the school year is appraised or joined in the party, under the same circumstances, it is possible to consider the additional points and make the operation of the B-M-D union team an integral part of the formative evaluation.

Thirdly, we can refer to the requirements for volunteers in the enrollment of foreign colleges and universities, and include students' social surveys and scientific research experience in the graduates' curriculum vitae to help students find employment in a pragmatic market economy.

Fourthly, the experience and gains in the B-M-D union team can give students a direct opportunity to understand social needs and improve students' social knowledge, practical experience, wisdom and courage for their students at school and after graduation. It also provides a platform for innovation and entrepreneurship.

\section{CONCLUSION}

The B-M-D integrated talent training model aims to achieve the objective of cultivating general education for students. It is the exploration of general education and specialty proposed in the The Thirteenth Five Year Plan for National Economic and Social Development (2016). The combination of education and training system is in line with the requirements. At the same time, relying on the integration of labor economics B-M-D union team building, young teachers in the process of joint research and cooperation with academic leaders, subtly change the value pursuit, spiritual realm. The motivation for behavior and the realization of the improvement of young teachers' academic ability and personality quality are conducive to the sustainable development of academic talent echelon and discipline construction. In the context of the rapid development of artificial intelligence and the need for innovation-driven economic development, the education of innovative talents must go beyond knowledge. The labor economics B-M-D union team will continue to work to enhance the key capabilities of team members. And in the course of operation, we will continue to improve the feasibility program and provide model reference for the training of other economicallyoriented professional talents with strong applicability.

\section{REFERENCES}

[1] The General Office of the CPC Central Committee and the General Office of the State Council. Opinions on Deepening the Reform of the Educational System and Mechanism [N]. People's Daily. September 25, 2017, version 01.

[2] Liu Guorui, Gao Shuren. The Historical Logic and Realistic Choice of the Transformation of Higher Education Development Methods[J]. Studies in Higher Education, 2015, (10): 1-7.

[3] Li Zhongshan. Facing the 21st Century to Improve the Management Level of University and the Efficiency of Running a School [J].Education Management Research, 1995,(3):14-17.

[4] Zhai Daguang. China's Higher Education should take the Path of Extensional Development [J]. Qiushi, 2003, (10): 51-54.

[5] Wang Hongcai. On the Connotation Development of Higher Education [J]. Educational Development Research, 2006, (7): 14-17.

[6] Yu Guang. Improving the Soft Power of Colleges and Universities, Promoting the Connotative Development of Higher Education [J]. 
Journal of National Academy of Education Administration, 2008, (6): 63-66.

[7] Zhang Dexiang, Lin Jie. The Historical Changes and Contemporary Implications of the Essence of Intensive Development of Higher Education [J]. Journal of National Academy of Education Administration, 2014, (11): 3-8.

[8] ZHENG Shushan. Innovative Talents Training Mode Building a Powerful Country with Human Resources[J]. Journal of National Institute of Education Administration, 2008, 126(6):7-9.

[9] Yuan Bentao, Li Wanhe, Wang Dingming, Characteristics of Professional Degree Talents Training Model: Based on the Perspective of Classification [J]. Higher Engineering Education Research, 2015, (2): 56-61.

[10] Huang Caiyu, Lu Jiaying, Dai Lingyun. A Brief Discussion on the Training Mode of Adult High-education Personnel in Colleges and Universities[J]. Chinese Adult Education, 2005, (2):14-15.
[11] Yan Daguang. Emphasis on Undergraduate Education: The Sign of Maturity of First-class Universities [J]. China Higher Education Research, 2016, (6):5-10.

[12] UNESCO International Education Development Council. Learning to survive - Today and Tomorrow in the World of Education [M]. Institute for Comparative Education, East China Normal University. Beijing: China Personnel Publishing House, 1996.

[13] Xiong Qingnian. The Reform of Personnel Training Mode must focus on Value Reconstruction [J]. Higher Education, 2010, (2): 14-15.

[14] Chen Dazhao. Three Major Research Topics Faced by Current College Graduates' Emp loy ment Guidance [J]. Journal of Guangdong Institute of Public Administration, 2000, (2): 78-81.

[15] Zhao Chunlei. From Extensive Development to Connotative Development- the Strategic Transformation of China's Higher Education Development [J]. Continuing Education Research 2015(2):18-20. 